\title{
The relationship of retinal vascular calibre to diabetes and retinopathy: the Australian Diabetes, Obesity and Lifestyle (AusDiab) study
}

\author{
G. Tikellis • J. J. Wang $\cdot$ R. Tapp $\cdot$ R. Simpson • \\ P. Mitchell • P. Z. Zimmet • J. Shaw $\cdot$ T. Y. Wong
}

Received: 30 April 2007 / Accepted: 7 August 2007 / Published online: 22 September 2007

(C) Springer-Verlag 2007

\begin{abstract}
Aims/hypothesis The aim of the study was to examine the relationship of retinal vascular calibre with glucose intolerance, diabetes and retinopathy in a population-based cohort. Methods The Australian Diabetes, Obesity and Lifestyle study recruited adults aged $\geq 25$ years old from across Australia. Participants were classified using an oral glucose tolerance test as having normal glucose tolerance (NGT), impaired glucose tolerance (IGT), impaired fasting glucose (IFG), known diabetes or newly diagnosed diabetes. Digital retinal photographs were taken of all participants with diabetes, IGT and IFG, and a sample of those with NGT, and graded for the presence of retinopathy. Retinal vascular calibre was measured from photographs by a computerassisted method.
\end{abstract}

G. Tikellis $\cdot$ J. J. Wang $\cdot$ T. Y. Wong $(\bowtie)$

Centre for Eye Research Australia, University of Melbourne,

32 Gisborne Street,

East Melbourne 3002 VIC, Australia

e-mail: twong@unimelb.edu.au

J. J. Wang $\cdot$ P. Mitchell

Centre for Vision Research, University of Sydney,

Sydney, Australia

R. Tapp • P. Z. Zimmet · J. Shaw $\cdot$ T. Y. Wong

International Diabetes Institute, Melbourne,

Melbourne, Australia

R. Tapp

Department of Epidemiology and Preventive Medicine,

Monash University,

Melbourne, Australia

R. Simpson

Eastern Health Research Unit, Box Hill Hospital,

Monash University,

Melbourne, Australia
Results Of the 1,998 participants with gradable retinal images, $16 \%$ had known diabetes, $17 \%$ newly diagnosed diabetes, $42 \%$ IGT, 6\% IFG and 19\% NGT. After multivariable adjustment, retinal arteriolar calibre was significantly larger in people with known diabetes $(178.9 \mu \mathrm{m})$ compared with participants with NGT (174.6 $\mu \mathrm{m}, p=0.02)$, IGT/IFG (175.5 $\mu \mathrm{m}, p=0.02)$ or newly diagnosed diabetes $(175.6 \mu \mathrm{m}, p=0.047)$. One SD increase in mean arteriolar calibre was associated with higher odds of diabetes compared with NGT (odds ratio $[\mathrm{OR}]=1.28$, $95 \% \mathrm{CI}=1.06-1.55)$. After multivariable adjustment, each SD increase in venular calibre was associated with higher odds of having retinopathy in persons with IGT/IFG $(\mathrm{OR}=1.78,95 \%$ $\mathrm{CI}=1.36-2.34)$ or in persons with diabetes $(\mathrm{OR}=1.68,95 \%$ $\mathrm{CI}=1.23-2.29$ ).

Conclusions/interpretation Diabetes is associated with larger retinal arteriolar calibre and retinopathy with larger retinal venular calibre. The contrasting associations may reflect different underlying pathophysiological processes in the natural history of diabetes.

Keywords Diabetes mellitus - Impaired fasting glucose · Impaired glucose tolerance - Retinopathy .

Retinal arteriolar calibre $\cdot$ Retinal venular calibre

$\begin{array}{ll}\text { Abbreviations } \\ \text { AusDiab } & \text { Australian Diabetes, Obesity and Lifestyle } \\ \text { CRAE } & \text { central retinal arteriolar equivalent } \\ \text { CRVE } & \text { central retinal venular equivalent } \\ \text { IFG } & \text { impaired fasting glucose } \\ \text { IGT } & \text { impaired glucose tolerance } \\ \text { KDM } & \text { known diabetes mellitus } \\ \text { NDM } & \text { newly diagnosed diabetes mellitus } \\ \text { NGT } & \text { normal glucose tolerance } \\ \text { OR } & \text { odds ratio }\end{array}$




\section{Introduction}

Diabetes mellitus is a major cause of morbidity and mortality worldwide [1, 2]. Retinopathy, a common microvascular complication of diabetes, is the leading cause of vision loss in adults of working age [3]. Elucidating the early pathophysiological changes involved in the development of glucose intolerance, diabetes and the subsequent development of retinopathy is important in identifying new treatment and preventative strategies [3, 4].

The development of retinal imaging technology has allowed non-invasive measurement of early structural changes in the retinal microvasculature $[5,6]$. Using these new methods, several studies have shown that changes in retinal vascular calibre are associated with the risk of developing type 2 diabetes [7, 8] and impaired fasting glucose (IFG) [9] and, among people with diabetes, with progression of retinopathy [10] and nephropathy [11]. However, there is a significant gap in the current literature concerning a clear understanding of how retinal vascular calibre changes with increasing severity of glucose intolerance [12]. This is important as persons with pre-diabetes status are known to also develop microvascular complications, including retinopathy [13-15].

In this study, we describe the distribution of retinal vascular calibre in persons with known and newly diagnosed diabetes and IGT, and examine the association of retinal calibre with diabetic retinopathy in people with and without diabetes in the Australian Diabetes, Obesity and Lifestyle (AusDiab) study.

\section{Methods}

Study population The AusDiab Study was conducted to assess the prevalence and impact of diabetes and diabetic complications in Australia and included a nationally representative sample of 11,247 adults aged $\geq 25$ years. The study was approved by the ethics committee of the International Diabetes Institute and informed consent for the study was obtained from all participants. The population, methods and response rates have been detailed and reported elsewhere [16]. In brief, this study surveyed samples from 42 randomly selected urban and rural areas of Australia. Of those who completed the household interview $(n=20,293), 55.4 \% \quad(n=11,247)$ attended the biomedical examination in 1999-2000. Participants had glucose tolerance tests, lifestyle parameters were assessed and cardiovascular risk factors were measured.

People identified through the AusDiab study as having diabetes ( $n=431$ with known diabetes [KDM] and 424 with newly diagnosed diabetes [NDM]), IFG or impaired glucose tolerance (IGT) $(n=1,155)$ and a random sample of people with normal glucose tolerance (NGT; $n=466$ ) were invited to participate in the complications component of the survey. Participants with NGT were selected using a systematic random sample of every $n$th person. The value of $n$ was dependent on the number of people expected on the day of testing, in order to obtain a sample size of ten per day. The overall response rate for the complications study was $89 \%(2,476$ of the 2,773 selected $)$, with a response rate of $91 \%$ among those with diabetes and $88 \%$ among those without diabetes [17].

Of the 2,476 participants who participated and had retinal photographs taken, 2,027 (82\%) had photographs that were of sufficient quality for retinal vascular calibre to be measured. We excluded seven $(0.3 \%)$ participants with unclassified diabetes status and a further $22(0.9 \%)$ participants with NGT who had retinopathy signs (e.g. isolated microaneurysms or haemorrhages) that may have been related to age and hypertension, leaving 1,998 participants who provided data for this analysis. The 478 participants with retinal images not included in the analysis were significantly older (62 vs 58 years, $p<0.001$ ), were more likely to have KDM (23 vs $16 \%, p=0.001$ ), and had a higher mean $\mathrm{HbA}_{1 \mathrm{c}}$ (5.86 vs $\left.5.68 \%, p=0.004\right)$ compared with those included in our analysis. A flow chart of participants in the AusDiab study is shown in Fig 1.

Diabetes status Diabetes classification of participants was based on the results of a 75-g OGTT using the 1999 WHO recommendations [18]. Participants were classified as $\mathrm{KDM}$ if they reported a history of physician-diagnosed diabetes and either were currently using treatment (insulin or oral hypo-glycaemic medications) or had fasting plasma glucose $\geq 7.0 \mathrm{mmol} / 1$ or $2 \mathrm{~h}$ plasma glucose $\geq 11.1 \mathrm{mmol} / \mathrm{l}$ at the examination. Participants without previously diagnosed diabetes who had a fasting plasma glucose concentration of $\geq 7.0 \mathrm{mmol} / 1$ or $2 \mathrm{~h}$ plasma glucose $\geq 11.1 \mathrm{mmol} / 1$ were classified as having NDM. Type 1 diabetes was defined as commencement of insulin treatment within 2 years of diagnosis (if diabetes onset was at age 40 years or later) and with current BMI $<27 \mathrm{~kg} / \mathrm{m}^{2}$. Otherwise they were classified as having type 2 diabetes.

IGT was defined when the fasting plasma glucose was $<7.0 \mathrm{mmol} / \mathrm{l}$ and the $2 \mathrm{~h}$ plasma glucose was $\geq 7.8$ and $<11.1 \mathrm{mmol} / \mathrm{l}$, and IFG when the fasting plasma glucose was $\geq 6.1$ and $<7.0 \mathrm{mmol} / \mathrm{l}$ and the $2 \mathrm{~h}$ plasma glucose was $<7.8 \mathrm{mmol} / \mathrm{l}$. All other participants were classified as having NGT. $H_{b A}$ c was determined from whole blood using boronate affinity HPLC (BioRad Variant Haemoglobin Testing System; BioRad, Hercules, CA, USA).

Retinal photography and retinopathy Non-mydriatic retinal photographs of both eyes, centred on the optic disc and the macula, were taken of participants using a digital retinal 
Fig. 1 Flowchart of persons selected to participate in the AusDiab study

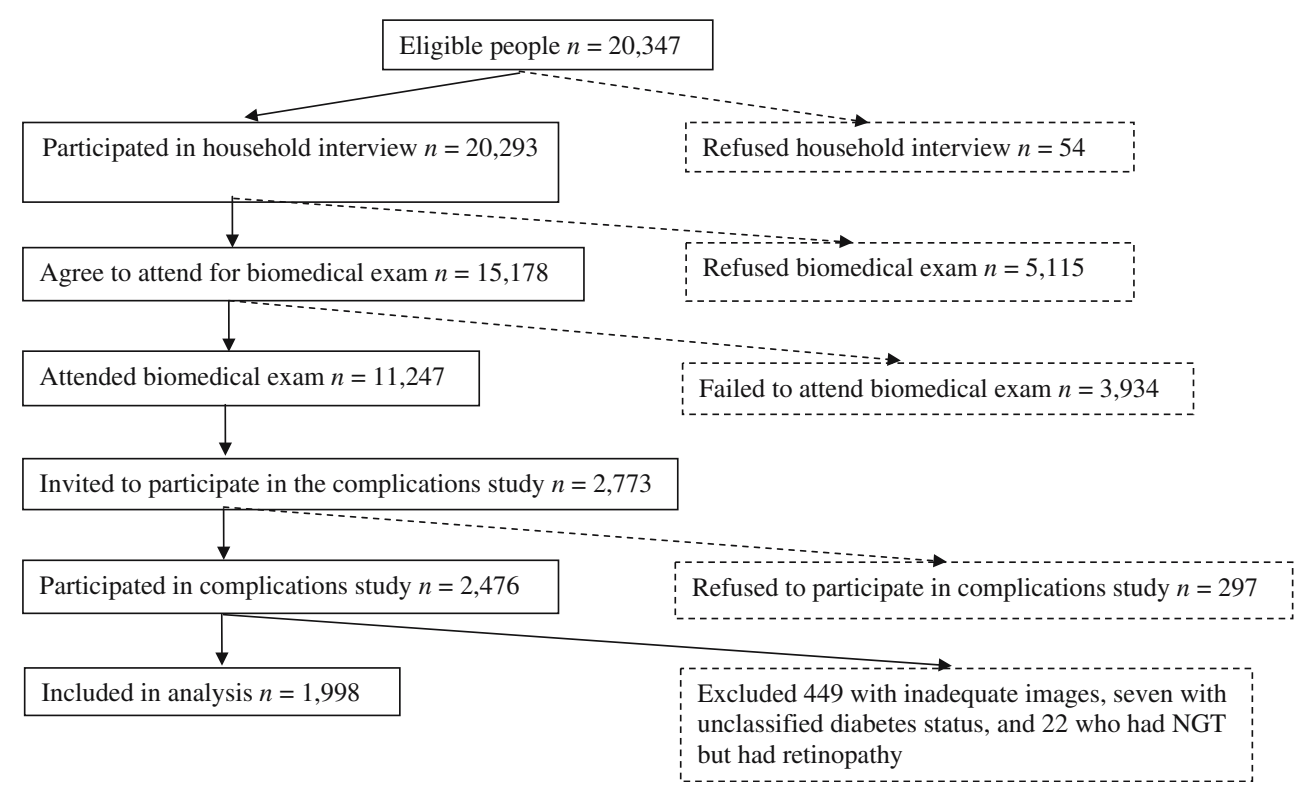

camera (Canon CR6-45NM; Canon, Lake Success, NY, USA) [17]. Photographs were graded for retinopathy by one assessor, who was masked to all participant characteristics. In people with IGT or IFG, retinopathy refers to the presence of at least one definite retinal haemorrhage and/or microaneurysm. In people with diabetes, the level of diabetic retinopathy was defined according to a simplified version of the Wisconsin grading system (absent, mild, moderate, severe non-proliferative diabetic retinopathy, and proliferative diabetic retinopathy) [19]. In our analysis, in people with diabetes, retinopathy was defined as mild or moderate retinopathy (i.e. it included the presence of at least one definite retinal haemorrhage and/or microaneurysm). The severity of diabetic retinopathy was based on data from the worst eye. There were no cases of severe non-proliferative diabetic retinopathy and only five cases of proliferative diabetic retinopathy. Because these five cases had received prior laser photocoagulation treatment, which may confound the assessment of retinal vessel calibre, they were excluded from the analyses.

A random re-grading of 167 retinal photographs by the same assessor (of those with and without retinopathy) showed a high level of intra-grader reliability (un-weighted $\kappa=0.73$ ).

Measurement of retinal vascular calibre Retinal vascular calibre was measured using a computer-assisted vessel measurement system (Retinal Analysis; Optimate, Madison, WI, USA) that uses microdensitometry to detect the vessel edge [20]. The measurement reflects the width of the erythrocyte column. Using a standard protocol, trained graders, masked to participant characteristics, retrieved an image from the network and identified each vessel as an arteriole or venule using the original digital image as a reference. The grader then selected a segment of each vessel coursing through a specified area (0.5-1.0 disc diameter surrounding the optic disc [zone B]). The software calculates the central and average width of five equidistant measurements of that vessel segment (in $\mu \mathrm{m}$ ). An intensity histogram of the central width measurement is displayed alongside the image (Fig. 2).

The grader assessed the validity of each measurement by evaluating the consistency of the histogram and visual image, and the correlation between the average and central widths. Once the diameters of all arterioles and venules within zone B had been assessed, the measurements were summarised into a central retinal arteriolar equivalent (CRAE) and central retinal venular equivalent (CRVE), according to formulas given by Hubbard et al. [21] and modified by Knudtson et al. [22]. The formula allows individual vessel diameters to be combined into summary indices reflecting the average arteriolar and venular diameters of that eye. Because retinal calibre measures are highly correlated between eyes, vascular calibre measurements of the left eye were used for all analyses.

The inter-grader intra-class correlation coefficients for the CRAE and CRVE measures were 0.92 and 0.96, respectively, and the intra-grader intra-class correlation coefficients for CRAE and CRVE were 0.83 and 0.92, respectively.

Measurement of other risk factors Plasma glucose, fasting serum total cholesterol, HDL- and LDL-cholesterol, and triacylglycerol were determined by enzymatic methods (AU600 analyser; Olympus, Tokyo, Japan). BP was measured in the supine position, with hypertension defined as systolic BP $>140 \mathrm{mmHg}$ and diastolic $\mathrm{BP}>90 \mathrm{mmHg}$ or current use of anti-hypertensive medications. BMI was calculated from measured weight and height. The level of 
Fig. 2 Sample digitised retinal photograph showing the retinal vessel diameter measurements in zone B

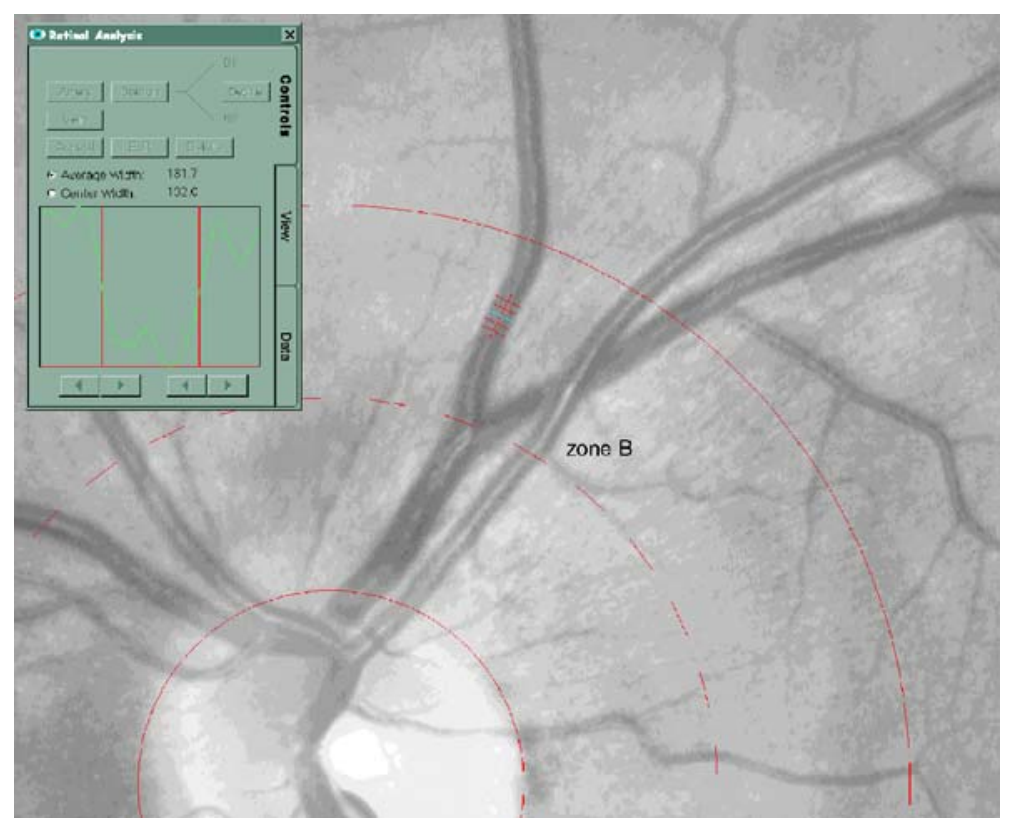

physical activity was categorised as 'sufficient' if there was more than 150 min of physical activity in the last week, and as 'insufficient' if the duration of physical activity in the last week was between 0 and $150 \mathrm{~min}$. Information on alcohol consumption, smoking, medication use and history of diabetes was obtained from a interviewer-administered questionnaire.

Statistical analysis Retinal vascular calibre (CRAE or CRVE) was assessed as a continuous variable (mean or per standard SD increase). Glycaemic status was categorised into four groups: NGT, IGT/IFG, NDM and KDM. Retinopathy was defined as absent or present.

Multinomial logistic regression models were constructed to assess the odds ratios (ORs) and 95\%CIs for the multicategorical outcome of glycaemic status (IGT/IFG, NDM and KDM, with NGT as the reference group) in association with retinal vascular calibre. The $p$ values for trends across the outcome categories were ascertained using Kendall's rank correlation test for categorical variables and one-way ANOVA for continuous measures comparing means. Binomial logistic regression models were used to assess the OR and $95 \% \mathrm{CI}$ of retinopathy among persons with diabetes (NDM/KDM) and among persons with IGT/IFG, in association with retinal vascular calibre. We constructed two models. In Model 1 we adjusted for age, sex, systolic BP, BMI, alcohol consumption (ever vs never), cigarette smoking (ever vs never), HDL-cholesterol and triacylglycerol levels. In Model 2 we adjusted additionally for CRVE in models that examined retinal arteriolar calibre and for CRAE in models that examined venular calibre. [23] For stratified analysis, an optimal glycaemic level defined as $\mathrm{HbA}_{1 \mathrm{c}}$ of $<7 \%$ was used, based on the recommended WHO recommendation for persons with diabetes [18], and diabetes duration was based on a median value for participants with $\mathrm{KDM}$ of 5 years. All significance levels were set at $p<0.05$. The data analysis was performed using SPSS version 12.0.1 for Windows (1999; SPSS, Chicago, IL, USA).

\section{Results}

Of the 1,998 participants included in this study, $320(16 \%)$ had KDM, 337 (17\%) had NDM, 960 (48\%) had IGT/IFG and 381 (19\%) had NGT. Of the 320 with KDM, $26(8 \%)$ had type 1 and 294 (92\%) had type 2 diabetes. Given that there were no significant differences between the two groups in terms of vascular calibre measurements, participants with type 1 and type 2 diabetes were combined as the KDM group (data not shown).

Table 1 compares the baseline characteristics of participants across the four groups of glycaemic status. Compared with the NGT group, participants with KDM were more likely to be men and to give a history of cigarette smoking, but were less likely to have ever consumed alcohol. People with IGT/IFG, KDM or NDM were significantly older, had higher systolic and diastolic BP, BMI and triacylglycerol levels but lower total cholesterol and HDL-cholesterol than those with NGT.

In the study population, CRAE was $175.73 \pm 25.0$ (mean \pm SD) $\mu \mathrm{m}$ and CRVE was $206.60 \pm 23.68 \mu \mathrm{m}$ (data not shown).

Associations of retinal arteriolar calibre CRAE and fasting plasma glucose were modestly and negatively correlated $(r=-0.07, p=0.002)$. Table 2 shows the distribution and association of CRAE by glycaemic and 
retinopathy status. After adjusting for co-variables in Model 1, participants with KDM had significantly larger mean CRAE than participants with NGT $(p=0.024$, data not shown), IGT/IFG $(p=0.016)$ or NDM $(p=0.047)$. For each SD increase in CRAE, the odds of having KDM compared with NGT were significantly increased $(\mathrm{OR}=1.28 ; 95 \% \mathrm{CI}=$ 1.06-1.55, Model 1). This association remained significant after further adjustment for CRVE in Model 2.

There were no significant associations between CRAE and retinopathy in persons with IGT/IFG (Table 2). In participants with diabetes (KDM or NDM), each SD larger CRAE was associated with increased odds of having retinopathy $(\mathrm{OR}=1.47 ; 95 \% \mathrm{CI}=1.11-1.94)$. However, with further adjustment for CRVE (Model 2), this association was no longer significant.

We found no linear relationship of CRAE with fasting plasma glucose after adjusting for age, sex, systolic and diastolic BP, BMI, cholesterol, LDL- and HDL-cholesterol, triacylglycerol, alcohol consumption and smoking $(\beta=-0.06$, $p=0.82$ ).

Associations of retinal venular calibre CRVE was not associated with fasting plasma glucose $(r=-0.002, p=$ 0.92). After adjusting for age, sex, systolic and diastolic BP, BMI, cholesterol, LDL- and HDL-cholesterol, triacylglycerol, alcohol consumption and smoking, there was no linear relationship between fasting plasma glucose and CRVE $(\beta=-0.36, p=0.16)$ in linear regression models.
Table 3 shows that, after adjusting for co-variables, no significant association of CRVE with glycaemic status was evident. However, in people with IGT/IFG or diabetes, each SD increase in CRVE was associated with a significantly higher risk of having retinopathy (IGT/IFG: OR $=1.36,95 \%$ $\mathrm{CI}=1.02-1.82$; diabetes: $\mathrm{OR}=1.49,95 \% \mathrm{CI}=1.06-2.09)$. Further adjustment for arteriolar calibre in Model 2 did not change these associations (Table 3).

Stratified analysis of CRAE and CRVE The association of larger retinal venular calibre with diabetic retinopathy was generally similar in subgroups stratified by the presence of hypertension, the glycaemic level and smoking status, and was also significant in people with diabetes duration $>5$ years (Table 4). Of interest was the finding that persons with NDM had an increased risk of having retinopathy with each SD increase in arteriole $(\mathrm{OR}=1.86,95 \% \mathrm{CI}=1.1 .02$ $3.37)$ and venular $(\mathrm{OR}=1.92,95 \% \quad \mathrm{CI}=1.04-3.54)$ diameter (Model 1). The risk was attenuated and became nonsignificant after further adjusting for CRVE or CRAE respectively in Model 2.

\section{Discussion}

In this large population-based cohort, we demonstrate variation in retinal arteriolar and venular calibre according to glycaemic status and retinopathy status. After controlling

Table 1 Baseline characteristics of participants in the AusDiab study population according to glycaemic status

\begin{tabular}{|c|c|c|c|c|c|c|}
\hline Characteristic & $\begin{array}{l}\text { All persons } \\
(n=1,998)\end{array}$ & $\begin{array}{l}\text { NGT } \\
(n=381)\end{array}$ & $\begin{array}{l}\mathrm{IGT} / \mathrm{IFG} \\
(n=960)\end{array}$ & $\begin{array}{l}\text { NDM } \\
(n=337)\end{array}$ & $\begin{array}{l}\text { KDM } \\
(n=320)\end{array}$ & $\begin{array}{l}p \text { value } \\
\text { for trend }\end{array}$ \\
\hline Male sex & $893(45)$ & $138(36)$ & $413(43)^{*}$ & $162(48)^{* *}$ & $177(55)^{* *}$ & $<0.001$ \\
\hline Ever drunk alcohol & $1719(86)$ & $344(90)$ & $833(87)$ & $259(81)^{*}$ & $238(81)^{* *}$ & 0.001 \\
\hline Ever smoked & $923(46)$ & $168(44)$ & $417(44)$ & $156(46)$ & $182(57)^{* *}$ & 0.001 \\
\hline Insufficient physical activity & $911(46)$ & $186(49)$ & $438(46)$ & $142(42)$ & $145(48)$ & 0.17 \\
\hline Retinopathy (either eye) & $153(8)$ & $0(0)$ & $66(6.9)$ & $17(5.0)$ & $70(22)^{* *}$ & $<0.001$ \\
\hline Age (years) & $58.07 \pm 13.93$ & $50.73 \pm 14.56$ & $58.85 \pm 13.54 * *$ & $60.86 \pm 13.03 * *$ & $62.82 \pm 11.58^{* *}$ & $<0.001$ \\
\hline $\mathrm{HbA}_{1 \mathrm{c}}(\%)$ & $5.68 \pm 1.14$ & $5.05 \pm 0.29$ & $5.29 \pm 0.34 * *$ & $5.99 \pm 1.12 * *$ & $7.32 \pm 1.65^{* *}$ & $<0.001$ \\
\hline Fasting plasma glucose $(\mathrm{mmol} / \mathrm{l})$ & $6.42 \pm 2.09$ & $5.95 \pm 1.29$ & $5.72 \pm 0.60 * *$ & $7.08 \pm 1.94 * *$ & $9.23 \pm 3.33 * *$ & $<0.001$ \\
\hline Post-load plasma glucose $(\mathrm{mmol} / \mathrm{l})$ & $9.16 \pm 3.36$ & $14.81 \pm 3.76$ & $8.70 \pm 1.32 * *$ & $12.72 \pm 3.78 * *$ & $15.05 \pm 3.84 * *$ & $<0.001$ \\
\hline Systolic BP (mmHg) & $\begin{array}{c}137.35 \pm \\
20.27\end{array}$ & $126.50 \pm 19.08$ & $137.53 \pm 19.13^{* *}$ & $144.01 \pm 20.13 * *$ & $143.52 \pm 19.53^{* *}$ & $<0.001$ \\
\hline Diastolic BP (mmHg) & $71.85 \pm 12.21$ & $66.74 \pm 10.85$ & $72.19 \pm 12.14^{* *}$ & $75.18 \pm 12.47 * *$ & $73.77 \pm 11.80 * *$ & $<0.001$ \\
\hline BMI $\left(\mathrm{kg} / \mathrm{m}^{2}\right)$ & $28.66 \pm 5.75$ & $25.93 \pm 4.56$ & $28.79 \pm 5.51 * *$ & $30.00 \pm 5.89 * *$ & $30.31 \pm 6.45^{* *}$ & $<0.001$ \\
\hline Total cholesterol $(\mathrm{mmol} / \mathrm{l})$ & $5.64 \pm 1.06$ & $5.42 \pm 1.03$ & $5.70 \pm 1.04 * *$ & $5.93 \pm 1.09 * *$ & $5.47 \pm 0.99$ & 0.13 \\
\hline HDL-cholesterol (mmol/l) & $1.37 \pm 0.39$ & $1.47 \pm 0.37$ & $1.40 \pm 0.40 * *$ & $1.30 \pm 0.40^{* *}$ & $1.24 \pm 0.34 * *$ & $<0.001$ \\
\hline Triacylglycerol (mmol/l) & $1.82 \pm 1.26$ & $1.26 \pm 0.93$ & $1.75 \pm 1.05^{* *}$ & $2.33 \pm 1.69 * *$ & $2.18 \pm 1.36^{* *}$ & $<0.001$ \\
\hline
\end{tabular}

Values are $n$ with $\%$ shown in parentheses, or mean \pm SD.

${ }^{*} p<0.05$ from multinomial logistic regression models for categorical characteristics and ANOVA for continuous characteristics with NGT as reference group.

${ }^{* *} p<0.005$ from multinomial logistic regression models for categorical characteristics and ANOVA for continuous characteristics with NGT as reference group. 
Table 2 Relationship of retinal arteriolar calibre by glycaemic and retinopathy status

\begin{tabular}{|c|c|c|c|c|c|c|}
\hline & \multirow[t]{3}{*}{$n$} & \multicolumn{5}{|c|}{ Retinal arteriolar calibre (CRAE) } \\
\hline & & \multirow[t]{2}{*}{ Mean $(\mu \mathrm{m})(\mathrm{SE})$} & \multicolumn{4}{|c|}{ OR $(95 \% \mathrm{CI})$ per one SD increase } \\
\hline & & & Model 1 & $p$ value & Model 2 & $p$ value \\
\hline \multicolumn{7}{|l|}{ Glycaemic status } \\
\hline NGT & 381 & $174.58(1.42)$ & 1.00 (reference) & - & 1.00 (reference) & - \\
\hline IGT/IFG & 960 & $175.45(0.96)$ & $1.07(0.93-1.25)$ & 0.68 & $1.12(0.94-1.33)$ & 0.21 \\
\hline Diabetes & 657 & $177.22(1.09)$ & $1.16(0.98-1.37)$ & 0.08 & $1.16(0.95-1.41)$ & 0.14 \\
\hline NDM & 337 & $175.56(1.41)$ & $1.07(0.89-1.29)$ & 0.23 & $1.02(0.82-1.27)$ & 0.88 \\
\hline KDM & 320 & $178.89(0.89)^{*}$ & $1.28(1.06-1.55)$ & 0.01 & $1.34(1.07-1.67)$ & 0.01 \\
\hline \multicolumn{7}{|l|}{ Retinopathy status } \\
\hline \multicolumn{7}{|l|}{ IGT/IFG } \\
\hline No retinopathy & 845 & $175.49(1.23)$ & 1.00 (reference) & - & 1.00 (reference) & - \\
\hline Retinopathy & 65 & $176.21(3.06)$ & $1.03(0.77-1.38)$ & 0.84 & $0.84(0.60-1.18)$ & 0.32 \\
\hline \multicolumn{7}{|l|}{ Diabetes } \\
\hline No retinopathy & 514 & $174.31(1.44)$ & 1.00 (reference) & - & 1.00 (reference) & \\
\hline Retinopathy & 83 & $182.37(2.80)$ & 1.47 (1.11-1.94) & 0.01 & $1.13(0.82-1.55)$ & 0.48 \\
\hline
\end{tabular}

Model 1 was adjusted for age, sex, systolic BP, BMI, alcohol use (ever vs never), cigarette smoking (ever vs never), and HDL-cholesterol and triacylglycerol levels.

Model 2 was adjusted for age, sex, systolic BP, BMI, alcohol use (ever vs never), cigarette smoking (ever vs never), and HDL-cholesterol and triacylglycerol levels, and additionally for CRVE in models that examined retinal arteriolar calibre and for CRAE in models that examined venular calibre.

${ }^{*} p<0.05$, comparing adjusted mean with NGT as reference group.

for other risk factors and venular calibre, persons with known diabetes were more likely to have larger arteriolar calibre than those with diabetes newly diagnosed in the study, or those with IGT or NGT. In contrast, larger retinal venular calibre was not significantly associated with diabetes status, but was significantly associated with the presence of retinopathy both in participants with IGT/IFG and in those with diabetes.

In analyses adjusted for age, sex, systolic BP, BMI, alcohol use, cigarette smoking, HDL-cholesterol and triacylglycerol, larger arterioles and venules were significantly associated with an increased risk of having retinopathy in participants who

Table 3 Relationship of retinal venular calibre by glycaemic and retinopathy status

\begin{tabular}{|c|c|c|c|c|c|c|}
\hline & \multirow[t]{3}{*}{$n$} & \multicolumn{5}{|c|}{ Retinal venular calibre (CRVE) } \\
\hline & & \multirow[t]{2}{*}{ Mean $(\mu \mathrm{m})(\mathrm{SE})$} & \multicolumn{4}{|c|}{ OR $(95 \% \mathrm{CI})$ per one SD increase } \\
\hline & & & Model 1 & $p$ value & Model 2 & $p$ value \\
\hline \multicolumn{7}{|l|}{ Glycaemic status } \\
\hline NGT & 381 & $209.44(1.41)$ & 1.00 (reference) & - & 1.00 (reference) & - \\
\hline IGT/IFG & 960 & $208.87(0.99)$ & $0.99(0.85-1.14)$ & 0.86 & $0.93(0.78-1.11)$ & 0.42 \\
\hline Diabetes & 657 & $210.63(1.08)$ & $1.08(0.92-1.27)$ & 0.37 & $1.00(0.83-1.21)$ & 0.99 \\
\hline NDM & 337 & $210.96(1.38)$ & $1.10(0.91-1.32)$ & 0.32 & $1.09(0.88-1.35)$ & 0.44 \\
\hline KDM & 320 & $210.31(1.38)$ & $1.06(0.88-1.28)$ & 0.54 & $0.91(0.73-1.14)$ & 0.41 \\
\hline \multicolumn{7}{|l|}{ Retinopathy status } \\
\hline \multicolumn{7}{|l|}{$\mathrm{IGT} / \mathrm{IFG}$} \\
\hline No retinopathy & 845 & $206.70(1.19)$ & 1.00 (reference) & - & 1.00 (reference) & - \\
\hline Retinopathy & 65 & $212.42(2.95)$ & $1.36(1.02-1.82)$ & 0.048 & $1.78(1.36-2.34)$ & 0.000 \\
\hline \multicolumn{7}{|l|}{ Diabetes } \\
\hline No retinopathy & 514 & $205.61(1.37)$ & 1.00 (reference) & - & 1.00 (reference) & - \\
\hline Retinopathy & 83 & $217.47(2.67)$ & $1.49(1.06-2.09)$ & 0.03 & $1.68(1.23-2.29)$ & 0.001 \\
\hline
\end{tabular}

Model 1 was adjusted for age, sex, systolic BP, BMI, alcohol use (ever vs never), cigarette smoking (ever vs never), and HDL-cholesterol and triacylglycerol levels.

Model 2 was adjusted for variables in Model 1 and for CRAE. 
Table 4 Association of retinal vascular calibre and retinopathy in participants with diabetes, stratified by hypertension, glycaemic level, diabetes duration and smoking status

\begin{tabular}{|c|c|c|c|c|c|c|c|c|c|c|}
\hline & \multirow[t]{3}{*}{$n$} & \multirow{3}{*}{$\begin{array}{l}n(\%) \\
\text { with } \\
\text { retinopathy }\end{array}$} & \multicolumn{4}{|c|}{ Retinal arteriolar calibre (CRAE) } & \multicolumn{4}{|c|}{ Retinal venular calibre (CRVE) } \\
\hline & & & \multicolumn{4}{|c|}{ OR $(95 \% \mathrm{CI})$ of retinopathy per one SD increase } & \multicolumn{4}{|c|}{ OR $(95 \% \mathrm{CI})$ of retinopathy per one SD increase } \\
\hline & & & Model 1 & $\begin{array}{l}p \\
\text { value }\end{array}$ & Model 2 & $\begin{array}{l}p \\
\text { value }\end{array}$ & Model 1 & $\begin{array}{l}p \\
\text { value }\end{array}$ & Model 2 & $\begin{array}{l}p \\
\text { value }\end{array}$ \\
\hline \multicolumn{11}{|c|}{ By hypertensive status } \\
\hline No hypertension & 181 & $14(8)$ & $\begin{array}{l}0.90 \\
\quad(0.45-1.80)\end{array}$ & 0.76 & $\begin{array}{l}0.56 \\
(0.25-1.30)\end{array}$ & 0.18 & $\begin{array}{l}1.88 \\
(0.98-3.57)\end{array}$ & 0.06 & $\begin{array}{l}2.43 \\
(1.13-5.21)\end{array}$ & 0.02 \\
\hline Hypertension & 412 & $65(16)$ & $\begin{array}{l}1.51 \\
(1.11-2.06)\end{array}$ & 0.008 & $\begin{array}{l}1.19 \\
(0.83-1.69)\end{array}$ & 0.35 & $\begin{array}{l}1.78 \\
(1.31-2.42)\end{array}$ & 0.000 & $\begin{array}{l}1.60 \\
(1.15-12.22)\end{array}$ & 0.01 \\
\hline \multicolumn{11}{|l|}{ By $\mathrm{HbA}_{1 \mathrm{c}}$ level } \\
\hline$<7 \%$ & 426 & $34(8)$ & $\begin{array}{l}1.42 \\
(0.95-2.14)\end{array}$ & 0.09 & $\begin{array}{l}1.06 \\
(0.66-1.72)\end{array}$ & 0.81 & $\begin{array}{l}1.84 \\
(1.20-2.84)\end{array}$ & 0.01 & $\begin{array}{l}1.73 \\
(1.08-2.94)\end{array}$ & 0.02 \\
\hline$\geq 7 \%$ & 166 & $46(28)$ & $\begin{array}{l}1.24 \\
(0.83-1.87)\end{array}$ & 0.30 & $\begin{array}{l}1.00 \\
(0.63-1.59)\end{array}$ & 0.99 & $\begin{array}{l}1.54 \\
(1.05-2.26)\end{array}$ & 0.03 & $\begin{array}{l}1.54 \\
(1.00-2.36)\end{array}$ & 0.049 \\
\hline \multicolumn{11}{|c|}{ By duration of diabetes } \\
\hline NDM & 309 & $17(6)$ & $\begin{array}{l}1.86 \\
(1.02-3.37)\end{array}$ & 0.043 & $\begin{array}{l}1.49 \\
(0.75-2.98)\end{array}$ & 0.26 & $\begin{array}{l}1.92 \\
(1.04-3.54)\end{array}$ & 0.04 & $\begin{array}{l}1.56 \\
(0.77-3.17)\end{array}$ & 0.22 \\
\hline $\mathrm{KDM} \leq 5$ years & 150 & $15(10)$ & $\begin{array}{l}0.82 \\
(0.42-1.61)\end{array}$ & 0.57 & $\begin{array}{l}0.67 \\
(0.31-1.45)\end{array}$ & 0.31 & $\begin{array}{l}1.20 \\
(0.64-2.25)\end{array}$ & 0.57 & $\begin{array}{l}1.45 \\
(0.70-3.02)\end{array}$ & 0.32 \\
\hline $\mathrm{KDM}>5$ years & 134 & $49(37)$ & $\begin{array}{l}1.62 \\
(1.05-2.51)\end{array}$ & 0.03 & $\begin{array}{l}1.20 \\
(0.74-1.93)\end{array}$ & 0.46 & $\begin{array}{l}2.41 \\
(1.48-3.92)\end{array}$ & 0.000 & $\begin{array}{l}2.24 \\
(1.33-3.77)\end{array}$ & 0.002 \\
\hline \multicolumn{11}{|l|}{ By smoking status } \\
\hline Never & 273 & $32(12)$ & $\begin{array}{l}1.31 \\
\quad(0.84-2.05)\end{array}$ & 0.23 & $\begin{array}{l}0.94 \\
\quad(0.56-1.57)\end{array}$ & 0.81 & $\begin{array}{l}1.90 \\
(1.23-2.92)\end{array}$ & 0.004 & $\begin{array}{l}1.94 \\
(1.19-3.18)\end{array}$ & 0.01 \\
\hline Current/past & 312 & $48(15)$ & $\begin{array}{l}1.46 \\
(1.03-2.06)\end{array}$ & 0.03 & $\begin{array}{l}1.19 \\
(0.80-1.77)\end{array}$ & 0.40 & $\begin{array}{l}1.66 \\
(1.17-2.35)\end{array}$ & 0.01 & $\begin{array}{l}1.53 \\
(1.02-2.28)\end{array}$ & 0.04 \\
\hline
\end{tabular}

Model 1 was adjusted for age, sex, systolic BP, BMI, alcohol use (ever vs never), cigarette smoking (ever vs never), and HDL-cholesterol and triacylglycerol levels.

Model 2 was adjusted for variables in Model 1 and for CRVE or CRAE as appropriate.

were newly diagnosed as having diabetes. However, further adjustment for CRAE or CRVE resulted in wider vessels being associated with an increased but not significant risk of developing diabetic retinopathy. Given that the main determinant of venular calibre is arteriolar calibre and that arteriolar calibre accounts for approximately $30 \%$ of the variability in venular calibre (T. Y. Wong, unpublished data) our findings may reflect over-adjustment of vessel calibre or a true biological occurrence.

The strengths of our study include its population-based sample, the classification of glucose tolerance status using the gold standard OGTT rather than just fasting or random blood glucose measurements, and the use of validated semiautomated software for measuring retinal vascular calibre.

Several important limitations of this study should be highlighted. First, the cross-sectional nature of our study cannot provide evidence for causal antecedent-consequent associations. Second, participants without gradable photographs were older and had higher systolic $\mathrm{BP}$ and $\mathrm{HbA}_{1 \mathrm{c}}$ levels, both of which are associated with an increased risk of developing diabetes. Thus, excluding these people may have led either to over- or under-estimation of the associations found. Third, it should be noted that computerassisted measurement of retinal vessel calibres from retinal photographs only measures the width of the reflective erythrocyte column and underestimates the true internal vessel calibre, as it does not measure the surrounding clear plasma zone. However, we believe erythrocyte column width is a good surrogate measure of internal vessel calibre as it appears to be proportional to internal retinal vessel calibre in animal studies, given that the ratio of the width of the plasma layer to internal vessel calibre for both arterioles and venules is relatively constant $(<10 \%$ of the internal diameter). Fundus fluorescein angiograms would provide a more accurate measure of external vessel calibre; however, such a procedure would not be feasible in a large epidemiological study. Fourth, although the differences in mean retinal vessel calibre among the various glycaemic groups were significant, the clinical significance of these findings requires further evaluation. The potential of using a computer-based system to evaluate retinal 
vessel calibre in identifying those at risk of developing diabetes and retinopathy is promising, but further research is clearly required before such systems can be implemented in clinical settings. Thus, our findings at present serve largely to identify changes in the retinal microvasculature that may be involved in the pathogenesis of diabetes and diabetic retinopathy. Fifth, retinal vessel calibre measurements were not synchronised on the cardiac cycle, which can result in 2$17 \%$ variation in measurements [24]. Nonetheless, this variation is likely to be random and would only tend to bias associations towards the null.

Our findings should be compared closely with those of other recent studies on the association between retinal vascular calibre and glycaemic status [7-10, 24-25]. These studies have not found consistent associations between retinal arteriolar calibre and the prevalence or incidence of diabetes. In the Multi-Ethnic Study of Atherosclerosis (MESA), wider arterioles were related to higher serum glucose levels [26], but prospective data from the Atherosclerosis Risk In Communities (ARIC) study [27] and the Beaver Dam Eye Study suggest that wider arteriolar calibre is associated with a lower risk of diabetes [28].

These three studies, however, did not differentiate between newly diagnosed diabetes and known diabetes, nor did they have information on glucose tolerance status. Our findings of wider arterioles in people with retinopathy corroborates findings in studies from Denmark [29, 30] and Iceland that support a hypothesis that a disturbance in the autoregulation of retinal arterioles resulting in arteriolar dilatation may be the cause of hyper-fusion, haemorrhage and microaneurysm formation resulting in macular oedema [31-33].

Our findings of an association between larger retinal venular calibre with retinopathy in persons with either IGT/ IFG or diabetes, independent of other factors and arteriolar calibre are more consistent with clinical experience and existing literature. Both cross-sectional and prospective data from the Wisconsin Epidemiological Study of Diabetic Retinopathy (WESDR) [10, 34] show that wider venular calibre is associated with severity and progression of retinopathy and with other microvascular complications, such as gross proteinuria and nephropathy [11]. However, despite the consistency of our study findings with the WESDR, the biological mechanisms that underlie these associations are uncertain, and may reflect increased retinal blood flow secondary to a combination of hyper-glycaemia [35] retinal hypoxia [9, 36], inflammation [37], increased lactate production [38] and/or endothelial dysfunction [39].

The contrasting associations of arteriolar and venular calibre with diabetes and retinopathy are interesting and may be important in understanding early microvascular changes in diabetes. These differences suggest that different microvascular processes are involved in the pathophysiology of diabetes development and subsequent microvascular complications. We can hypothesise that changes in arteriolar calibre occur early in diabetes, whereas changes in venular calibre are late manifestations with the onset of microvascular complications. Further research is clearly needed to test this hypothesis.

In conclusion, we found that larger arteriolar calibre was associated with known diabetes, and larger retinal venular calibre was associated with the presence of retinopathy in persons with diabetes or with IGT/IFG. These findings suggest that variations in retinal arteriolar and venular calibre may reflect different pathophysiological processes. It is possible that arteriolar calibre changes occur early in the course of diabetes, but that venular calibre changes are only associated with the onset of microvascular complications such as retinopathy. Studying changes in retinal vascular calibre may therefore provide important insights into the pathophysiology and natural history of diabetes and its microvascular complications.

Acknowledgements This study was supported by the National Health and Medical Research Council grants 350448 and 233200, and a Sylvia and Charles Viertel Charitable Foundation grant. We are grateful to S. Murray (AusDiab project manager) and S. Fournel (AusDiab administration) for their invaluable contribution to the study. We would also like to thank M. Dalton (AusDiab field coordinator 1999-2000), T. Whalen and A. Bonney (AusDiab field coordinators 2004-2005), all the AusDiab support staff, and especially the participants for volunteering their time to be involved in the study.

Duality of interest The authors declare that there is no duality of interest associated with this manuscript.

\section{References}

1. Dunstan D, Zimmet P, Welborn T et al (2002) The rising prevalence of diabetes and impaired glucose tolerance. Diabetes Care 25:829-834

2. Zimmet P (1999) Diabetes epidemiology as a trigger to diabetes research. Diabetologia 42:499-518

3. Engelgau M, Narayan K, Herman W (2000) Screening for type 2 diabetes. Diabetes Care 23:1563-1580

4. Mitchell P, Smith W, Wang J, Attebo K (1998) Prevalence of diabetic retinopathy in an older community. The Blue Mountains Eye Study. Ophthalmology 105:406-411

5. Hubbard L, Brothers R, King W et al (1999) Methods for evaluation of retinal microvascular abnormalities associated with hypertension/sclerosis in the Atherosclerosis Risk in Communities Study. Ophthalmology 106:2269-2280

6. Wong TY, Knudtson MD, Klein R, Klein BE, Meuer SM, Hubbard LD (2004) Computer-assisted measurement of retinal vessel diameters in the Beaver Dam Eye Study: methodology, correlation between eyes, and effect of refractive errors. Ophthalmology 111:1183-1190

7. Wong TY, Klein R, Sharrett AR et al (2002) Retinal arteriolar narrowing and risk of diabetes mellitus in middle-aged persons. JAMA 287:2528-2533

8. Wong TY, Shankar A, Klein R, Klein BE, Hubbard LD (2005) Retinal arteriolar narrowing, hypertension, and subsequent risk of diabetes mellitus. Arch Intern Med 165:1060-1065 
9. Ikram MK, Janssen JA, Roos AM et al (2006) Retinal vessel diameters and risk of impaired fasting glucose or diabetes: the Rotterdam study. Diabetes 55:506-510

10. Klein R, Klein B, Moss S, Wong T, Sharrett AR (2006) Retinal vascular caliber in persons with type 2 diabetes. The Wisconsin Epidemiological Study of Diabetic Retinopathy: XX. Ophthalmology 113:1488-1498

11. Wong T, Shankar A, Klein R, Klein B (2004) Retinal vessel diameters and the incidence of gross proteinuria and renal insufficiency in people with type 1 diabetes. Diabetes 53:179-184

12. Nguyen T, Wong T (2006) Retinal vascular manifestations of metabolic disorders. Trends Endocrinol Metab 17:262-268

13. Wong T, Barr E, Tapp R et al (2005) Retinopathy in persons with impaired glucose metabolism: the Australian Diabetes Obesity and Lifestyle (AusDiab) study. Am J Ophthalmol 140:1157-1159

14. Diabetes Prevention Program Research Group (2007) The prevalence of retinopathy in impaired glucose tolerance and recent-onset diabetes in the Diabetes Prevention Program. Diabet Med 24:137-144

15. Barr E, Wong T, Tapp R, Harper CA, Zimmett PZ, Atkins, R, Shaw JE, AusDiab Steering Committee (2006) Is peripheral neuropathy associated with retinopathy and albuminuria in individuals with impaired glucose metabolism? The 1999-2000 AusDiab. Diabetes Care 29:1114-1116

16. Dunstan D, Zimmet P, Welborn T et al (2002) The Australian Diabetes, Obesity and Lifestyle Study (AusDiab) — methods and response rates. Diabetes Res Clin Pract 57:119-129

17. Tapp R, McCarty D, Shaw J et al (2003) The prevalence and risk factors associated with diabetic retinopathy in the Australian population. Diabetes Care 26:1731-1737

18. World Health Organization (1999) Definition, diagnosis and classification of diabetes mellitus and its complications. Part 1: diagnosis and classification of diabetes mellitus. Department of Noncommunicable Disease Surveillance, Geneva

19. Aldington S, Kohner E, Meuer S, Klein R, Sjolie A (1995) Methodology for retinal photography and assessment of diabetic retinopathy: EURODIAB IDDM Complications Study. Diabetologia 38:437-444

20. Wong TY, Knudtson MD, Klein R, Klein BE, Meuer SM, Hubbard LD (2004) Computer-assisted measurement of retinal vessel diameters in the Beaver Dam Eye Study: methodology, correlation between eyes, and effect of refractive errors. Ophthalmology 111:1183-1190

21. Hubbard LD, Brothers RJ, King WN et al (1999) Methods for evaluation of retinal microvascular abnormalities associated with hypertension/sclerosis in the Atherosclerosis Risk in Communities Study. Ophthalmology 106:2269-2280

22. Knudtson MD, Lee KE, Hubbard LD, Wong TY, Klein R, Klein BE (2003) Revised formulas for summarizing retinal vessel diameters. Curr Eye Res 27:143-149
23. Liew G, Sharrett AK, R, Klein R et al (2007) Measurement of retinal vascular caliber: issues and alternatives to using the arteriole to venule ratio. Invest Ophthalmol Vis Sci 48:52-57

24. Knudtson MD, Klein BE, Klein R et al (2004) Variation associated with measurement of retinal vessel diameters at different points in the pulse cycle. Br J Ophthalmol 88:57-61

25. Bulpitt C, Dollery C, Kohner E (1970) The marginal plasma zone in the retinal microcirculation. Cardiovasc Res 4:207-212

26. Wong T, Islam A, Klein R et al (2006) Retinal vascular caliber, cardiovascular risk factors, and inflammation: the Multi-Ethnic Study of Atherosclerosis (MESA). Invest Ophthalmol Vis Sci 47:2341-2350

27. Wong TY, Klein R, Sharrett AR et al (2002) Retinal arteriolar narrowing and risk of diabetes mellitus in middle-aged persons. JAMA 287:2528-2533

28. Wong TY, Shankar A, Klein R, Klein BE, Hubbard LD (2005) Retinal arteriolar narrowing, hypertension, and subsequent risk of diabetes mellitus. Arch Intern Med 165:1060-1065

29. Frederiksen C, Jeppesen P, Knudsen S, Poulsen P, Mogensen C, Bek T (2006) The blood pressure-induced diameter response of retinal arterioles decreases with increasing diabetic maculopathy. Graefes Arch Clin Exp Ophthalmol 244:1255-1261

30. Stefansson E (1997) Ocular oxygenation and the treatment of diabetic retinopathy. Br J Ophthalmol 81:274-278

31. Bek T (1999) Diabetic maculopathy caused by disturbances in retinal vasomotion. A new hypothesis. Acta Ophthalmol Scand $77: 376-380$

32. Kristinsson JK, Gottfredsdottir MS, Stefansson E (1997) Retinal vessel dilatation and elongation precedes diabetic macular oedema. Br J Ophthalmol 81:274-278

33. Gardner TW, Antonetti DA, Barber AJ, LaNoue KF, Levison SW (2002) Diabetic retinopathy: more than meets the eye. Surv Ophthalmol 47(Suppl 2):S253-S262

34. Klein R, Klein BE, Moss SE et al (2004) The relation of retinal vessel caliber to the incidence and progression of diabetic retinopathy: XIX: the Wisconsin Epidemiologic Study of Diabetic Retinopathy. Arch Opthalmol 122:76-83

35. Grunwald JE, Riva CE, Baine J, Brucker AJ (1992) Total retinal volumetric blood flow rate in diabetic patients with poor glycemic control. Invest Ophthalmol Vis Sci 33:356-363

36. Saldivar E, Cabrales P, Tsai AG, Intaglietta M (2003) Microcirculatory changes during chronic adaptation to hypoxia. Am J Physiol Heart Circ Physiol 285:H2064-H2071

37. Ikram MK, de Jong FJ, Vingerling JR et al (2004) Are retinal arteriolar or venular diameters associated with markers for cardiovascular disorders? The Rotterdam Study. Invest Ophthalmol Vis Sci 45:2129-2134

38. Clermont A, Bursell S (2007) Retinal blood flow in diabetes. Microcirculation 14:49-61

39. Caballero AE (2005) Metabolic and vascular abnormalities in subjects at risk for type 2 diabetes: the early start of a dangerous situation. Arch Med Res 36:241-249 